\title{
Pengujian Ekstrak Tumbuhan \\ Vitex trifolia L., Acorus colomus L., dan Andropogon nardus L. terhadap Hama Pasca Panen Araecerus fasciculatus De Geer (Coleoptera: Anthribidae) pada Biji Kakao
}

\author{
SYLVIA SJAM, MELINA, DAN SULAEHA THAMRIN \\ Jurusan Hama dan Penyakit Tumbuhan \\ Fakultas Pertanian Universitas Hasanuddin \\ (diterima Oktober 2009, disetujui Januari 2010)
}

\begin{abstract}
Bioassay of Vitex trifolia L., Acorus colomus L., and Andropogon nardus L. On Cocoa Pest Araecerus fasciculatus De Geer (Coleoptera: Anthribidae). Araecerus fasciculatus (Coleoptera: Anthribidae) is a primary pest mostly found in cocoa bean storage. Controlling $A$. fascuculatus is highly necessary, as this action would also reduce infestation of secondary pests. Utilization of natural materials as bait or trap is one applicable method to lessen damage and loss during storage. Vitex trifolia L., Acorus colomus L., and Andropogon nardus L are plant species that posess insecticidal properties that can be used to control post harvest pests. Materials used in this experiment are leaves of $V$. trifolia, rhizome of $A$. colomus and leaves of $A$. nardus. The three types of materials are blended and sieved with 300 mesh until finely broken up for make powder formulation. As much as $1 \mathrm{~g}$ of powder extract was taken then mixed with additional substract (water $+\mathrm{CMC}+$ saw dusts). The mixtures were then shaped in the form of ellipse resembling cocoa beans with approximately similar weight of $0.6 \mathrm{~g}$ ( \pm 20 beans). Results show that $V$. trifolia and $A$. nardus are highly repellent $(90.5 \%$ and $94.5 \%)$ to $A$. fasciculatus, and crhizome of $A$. colomus is attractant to $A$. fasciculatus.
\end{abstract}

KEY WORDS: Araecerus fasciculatus, Vitex trifolia, Acorus colomus, Andropogon nardus, cocoa, repellant, attractant

\section{PENDAHULUAN}

Tanaman kakao (Theobroma cacao

L.) merupakan komoditas perkebunan yang memiliki prospek yang sangat baik sebagai sumber devisa. Kualitas biji kakao Indonesia tergolong rendah sehingga 40\% dari 300.000 ton ekspor biji kakao Indonesia ke Amerika Se- rikat setiap tahunnya mengalami penahanan langsung (automatic detention) oleh USFDA. Automatic detention menyebabkan potongan harga yang cukup tinggi sekitar $15 \%$ dari harga rata-rata kakao dunia. Salah satu penyebab rendahnya kualitas biji kakao adalah adanya infestasi serangga hama, padahal persyaratan kualitas/ mutu biji kakao adalah tidak adanya 
serangga hidup dalam biji kakao yang dapat menyebabkan penahanan langsung oleh negara tujuan (Anonim 2002).

Araecerus fascuculatus De Geer (Coleoptera : Anthribidae) merupakan hama primer yang sangat banyak ditemukan di penyimpanan biji kakao sehingga perlu upaya pengendalian untuk mengurangi infestasi hama selama di penyimpanan. Pengendalian A. fasciculatus sebagai hama primer sangat penting karena akan mengurangi infestasi dari hama-hama sekunder. Hama sekunder dapat berkembang dengan baik jika biji kakao telah terserang oleh hama primer sehingga kerusakan hasil biji kakao akan semakin besar (Dobie et al. 1991).

Penggunaan bahan alami tanaman sebagai umpan atau perangkap merupakan salah satu cara yang akhir-akhir ini dikembangkan untuk mengurangi kerusakan hasil selama di penyimpanan. Beberapa senyawa-senyawa yang terkandung dalam bahan tanaman dapat memiliki sifat repelensi dan atraktan. Senyawa-senyawa tersebut tidak memiliki efek negatif terhadap manusia dan tidak meninggalkan residu pada komoditas atau makanan yang disimpan. Cara ini merupakan salah satu alternatif dalam pengelolaan hama secara terpadu di penyimpanan untuk mengurangi populasi hama dan juga merupakan salah satu metode untuk mengendalikan serangga dewasa.
Tanaman legundi (Vitex trifolia L.), jeringau (Acorus colomus L.), sereh liar (Andropogon nardus L.) dapat dimanfaatkan untuk pengendalian $A$. fasciculatus pada biji kakao di penyimpanan. Penelitian ini mempelajari respon ketertarikan dan penolakan hama $A$. fasciculatus terhadap ketiga bahan tanaman yang di uji.

\section{BAHAN DAN METODE}

Penelitian ini dilaksanakan di Laboratorium Toksikologi Jurusan Hama dan Penyakit Tumbuhan, Fakultas Pertanian dan Kehutanan, Universitas Hasanuddin (UNHAS). Penelitian dilakukan pada Bulan Juni hingga November 2008.

\section{A. Perbanyakan Serangga}

Serangga $A$. fasciculatus yang digunakan dalam percobaan ini berasal dari Balai Karantina Tumbuhan Makassar, yang kemudian diperbanyak di Laboratorium Toksikologi UNHAS. Serangga dewasa diinfestasikan ke dalam toples perbanyakan ukuran diameter $25 \mathrm{~cm}$ yang berisi biji kakao sebagai pakan. Bagian tutup toples dilubangi dan ditutup dengan kain kasa berwarna putih. Serangga dewasa yang telah diinfestasikan dibiarkan bertelur hingga berkembang menjadi serangga dewasa. Selanjutnya serangga dewasa yang baru keluar diinfestasikan kembali pada biji kakao yang belum terinfestasi. Serangga uji dibiakkan pada suhu $27^{\circ} \mathrm{C}$, dengan $\mathrm{RH} 70 \%$. Demikian perbanyakan ini dilakukan 
secara terus menerus hingga didapatkan A. fasciculatus dalam jumlah yang banyak dan umur yang seragam. Hasil perbanyakan ini yang digunakan untuk pengujian.

\section{B. Pembuatan Sediaan Pelet Tumbuhan}

\section{Pembuatan Sediaan Bubuk Vitex trifolia dan Acorus colomus.}

Daun $V$. trifolia dan rimpang $A$. colomus dibersihkan dari kotoran dengan cara dicuci. Daun $V$. trifolia dipisahkan dari tangkainya dan rimpang A. colomus diiris tipis-tipis, kemudian kedua bahan ini dikeringanginkan secara terpisah. Setelah itu masing-masing bahan tanaman di blender kemudian diayak dengan ayakan 300 mesh sampai didapatkan bubuk dengan ukuran yang seragam. Sebanyak 1 gram bubuk ekstrak dicampur dengan bahan penambah yaitu (air + CMC + serbuk gergaji). Hasil campuran dibentuk menjadi bulat lonjong yang menyerupai biji kakao dengan berat yang seragam 0,6 gram ( \pm 20 butir).

\section{Pembuatan sediaan Minyak Andropogon nardus}

Minyak $A$. nardus yang digunakan adalah minyak hasil penyulingan (destilasi). Diambil 0,50 $\mathrm{ml}$ dari hasil penyulingan tersebut, kemudian dicampur dengan bahan penambah (air + CMC + serbuk gergaji). Selanjutnya hasil dari campuran tersebut dibentuk bulat lonjong menyerupai biji kakao dengan berat yang sama (0,6 gram) $( \pm$ 20 butir).

\section{Metode Penelitian}

Penelitian disusun berdasarkan rancangan acak lengkap. Metode pengujian yang digunakan adalah metode pilihan dengan menggunakan olfaktometer untuk mengetahui sifat repelensi dan atraktan dari jenis tumbuhan yang digunakan. Pengujian ini dilakukan dengan 2 cara yaitu:

\section{Metode I}

Setiap sediaan pelet tumbuhan ditempatkan pada satu olfaktometer dan pada tiap olfaktometer individual terdapat 2 tabung yang merupakan perlakuan. Pengulangan dalam percobaan ini menggunakan olfaktometer yang berbeda, dengan 4 kali ulangan yaitu: a. PO (biji kakao) dan P1 (biji kakao + sediaan butiran $V$. trifolia), b. PO (biji kakao) dan P2 (biji kakao + sediaan butiran $A$. colomus), c. PO (biji kakao) dan P3 (biji kakao + sediaan butiran A. nardus)

Setiap tabung perlakuan diisi dengan 7 butir biji kakao dan salah satu dari tabung tersebut diletakkan 1 butir sediaan tumbuhan. Selanjutnya diinfestasikan 10 pasang kumbang $A$. fasciculatus yang baru menjadi dewasa (umur antara $1-3$ hari).

\section{Metode II}

Setiap sediaan butiran tumbuhan ditempatkan pada satu olfaktometer individual. Pada setiap olfaktormeter individual dilengkapi dengan 4 buah 
tabung yang merupakan perlakuan. Pengulangan dalam percobaan ini menggunakan olfaktometer yang berbeda, dengan 4 kali ulangan yaitu: PO = biji kakao, P1= biji kakao + sediaan butiran $V$. trifolia, $\mathrm{P} 2=$ biji kakao + sediaan butiran $A$. colomus, $\mathrm{P} 3=$ biji kakao + sediaan butiran $A$. nardus.

Pada masing-masing tabung diletakkan 7 butir biji kakao dan 1 butir sediaan tumbuhan kecuali pada tabung PO (biji kakao). Sediaan tumbuhan tersebut ditempatkan pada masingmasing ujung tabung, selanjutnya ke dalam satu olfaktometer diinfestasikan 15 pasang imago kumbang $A$. fasciculatus yang berumur antara 1-3 hari.

\section{Parameter Pengamatan:}

\section{a. Banyaknya Serangga yang}

\section{Datang}

Jumlah imago A. fasciculatus dihitung berdasarkan banyaknya imago yang terdapat pada masing-masing tabung olfaktometer individual. Perhitungan populasi imago yang datang dilakukan setiap hari sejak infestasi dan dikumulatifkan setiap minggu. Persentase repelensi dihitung menggunakan persamaan sebagai berikut :

Persentase repelensi $=(\underline{\mathrm{A}-\mathrm{N}}) \times 100 \%$

A

Keterangan :

$\mathrm{A}=$ Banyaknya serangga pada kontrol

$\mathrm{N}=$ Banyaknya serangga pada perlakuan

Klasifikasi tingkat repelensi sbb:

Klas $0=$ Tidak ada repelensi
Klas $1=0-20 \%$

Klas $2=20,1-40 \%$

Klas $3=40,1-60 \%$

Klas $4=60,1-80 \%$

Klas $5=80,1-100 \%$

Persentase atraktan dihitung dengan menggunakan persamaan :

Persentase atraktan $=\underline{(\mathrm{N}-\mathrm{A})} \times 100 \%$ $\mathrm{N}$

Keterangan :

$\mathrm{A}=$ Banyaknya serangga pada kontrol

$\mathrm{N}=$ Banyaknya serangga pada perlakuan

Klasifikasi tingkat ketertarikan sbb:

Klas $0=$ Atraktan negative

Klas $1=0-20 \%$

Klas $2=20,1-40 \%$

Klas $3=40,1-60 \%$

Klas $4=60,1-80 \%$

Klas $5=80,1-100 \%$

\section{b. Tingkat Ketahanan Bahan} Tanaman

Pengamatan ini bertujuan untuk mengetahui berapa lama bahan tanaman uji efektif dalam menarik atau menolak A. fasciculatus. Pengamatan dilakukan setiap hari. Setelah 6 hari dilakukan penggantian biji kakao dan serangga $A$. fasciculatus yang baru. Hal serupa dilakukan pada ulangan yang lainnya sebanyak 5 kali. Lamanya sifat perlakuan akan terlihat jika tidak ada lagi serangga yang tertarik ataupun yang tertolak pada komponen perlakuan atau jumlah $A$. fasciculatus 
yang mendekati atau menjauhi perlakuan atau sama dengan jumlah $A$. fasciculatus yang mendekati atau menjauhi perlakuan biji kakao.

\section{HASIL DAN PEMBAHASAN}

\section{a. Jumlah $A$. fasciculatus yang \\ Tertarik pada Tiga Jenis \\ Tumbuhan (Metode I)}

Hasil pengamatan terhadap banyaknya imago $A$. fasciculatus yang tertarik pada tabung perlakuan olfaktometer pada pengamatan minggu ke-1 sampai ke-5 disajikan pada Gambar 1.

Berdasarkan hasil pengamatan terlihat pada semua perlakuan antara tabung perlakuan biji kakao (PO) sebagai kontrol dengan tabung perlakuan sediaan butiran $V$. trifolia, A. colomus, dan A. nardus (P1, P2, dan P3) memperlihatkan perbedaan yang nyata, terutama pada pengamatan minggu ke1 sampai minggu ke-4 (Gambar 1). Pada tabung perlakuan $V$. trifolia (P1) dan $A$. nardus (P3) jumlah $A$. fasciculatus yang tertarik lebih banyak terdapat pada kontrol, sedangkan pada tabung perlakuan $A$. colomus (P2) jumlah $A$. fasciculatus yang tertarik lebih banyak, dibanding kontrol.

\section{b. Rata-rata Jumlah $A$. fasciculatus yang Tertarik pada Tiga Jenis Tumbuhan (Metode II)}

Hasil pengamatan terhadap banyaknya imago A. fasciculatus yang tertarik pada tabung perlakuan olfaktometer dengan pengamatan minggu ke 1 sampai minggu ke 5 terlihat pada Gambar 2.

Jumlah $A$. fasciculatus yang tertarik pada perlakuan biji kakao (PO) dan A. colomus (P2) mencapai puncaknya pada pengamatan minggu ke-1 sampai ke-3 sedangkan pada $V$. trifolia (P1) dan $A$. nardus (P3) mencapai puncaknya pada minggu ke-4 setelah infestasi. Hasil pengamatan memperlihatkan bahwa $V$. trifolia dan $A$. nardus bersifat sangat repelen terhadap $A$. fasciculatus. Hal ini dapat dilihat pada Gambar 1 dan 2.

\section{c. Persentase Ketertarikan (Atraktan) dan Repelensi Ketiga Jenis Sediaan Butiran Tumbuhan terhadap Imago $A$. fasciculatus}

Pengamatan tingkat repelensi dan atraktan ketiga jenis sediaan butiran terhadap imago A. fasciculatus selama pengamatan minggu ke-1 sampai minggu ke-5 dapat dilihat pada banyaknya imago A. fasciculatus.

Hasil pengamatan memperlihatkan bahwa $V$. trifolia dan $A$. nardus bersifat sangat repelen terhadap $A$. fasciculatus. Rata-rata A. fasciculatus yang terdapat pada perlakuan $V$. trifolia dan $A$. nardus lebih rendah dibandingkan dengan perlakuan biji kakao. Pada $V$. trifolia diduga terdapat aroma yang tidak disukai oleh $A$. fasciculatus sehingga jumlah serangga yang datang sangat sedikit jika dibandingkan dengan perlakuan biji kakao. Menurut Heyne (2004), V. trifolia mengandung sedikit alkaloid dan aromanya sangat 

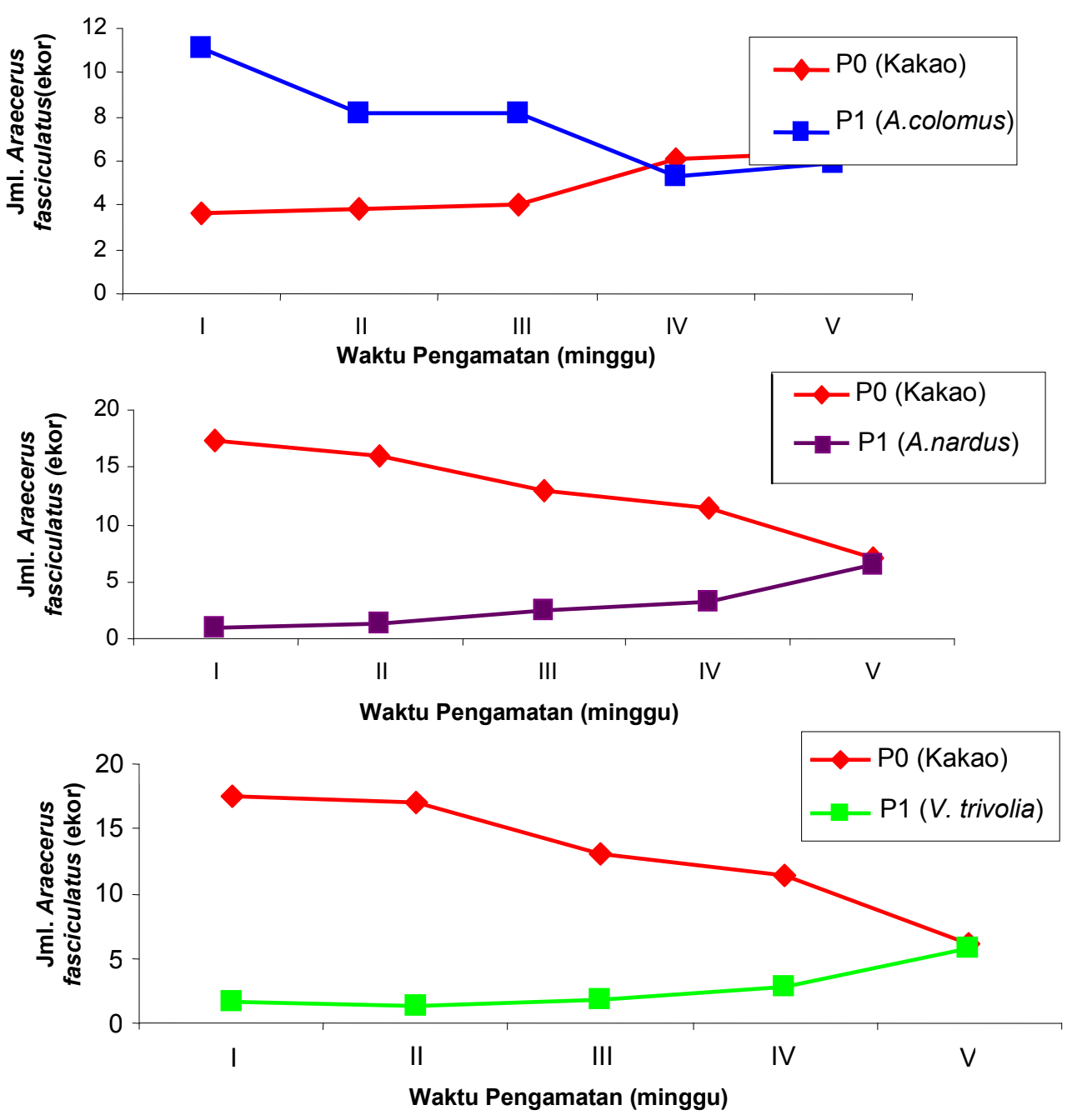

Gambar 1. Rata-rata jumlah A. fasciculatus yang tertarik pada masing-masing pengamatan (metode I)

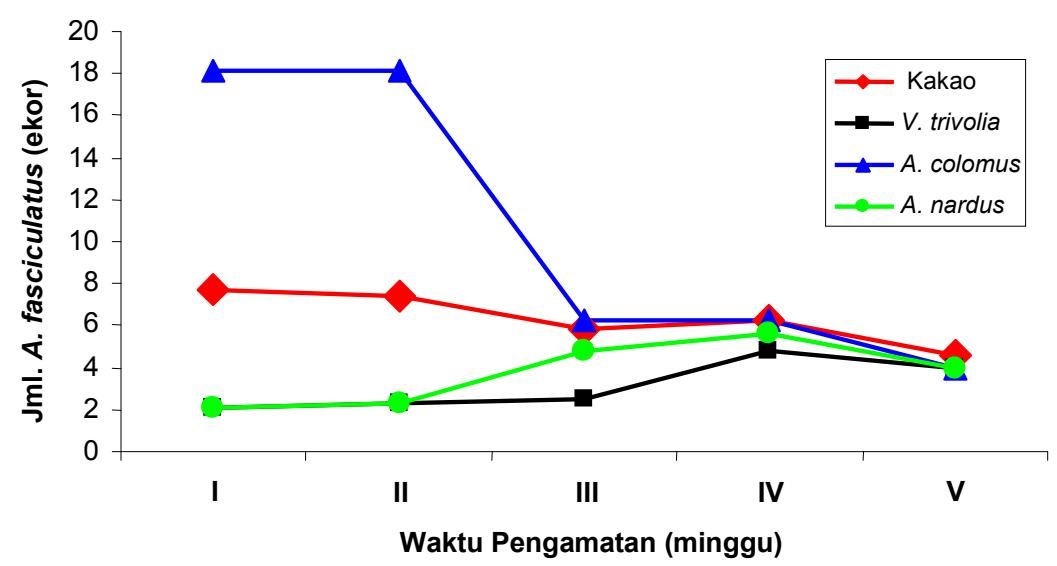

Gambar 2. Rata-rata jumlah $A$. fasciculatus yang tertarik pada beberapa bahan tanaman 
Tabel 1. Kelas repelensi dan atraktan ketiga jenis sediaan butiran terhadap imago A. fasciculatus

\begin{tabular}{lccccc}
\hline \hline Sediaan butiran & Pengamatan & \multicolumn{2}{c}{ Persentase (\%) } & Kelas & Kelas \\
\cline { 3 - 4 } tanaman & (minggu) & Repelensi & Atraktan & Repelensi & Atraktan \\
\hline Vitex trifolia & I & 90,5 & - & 5 & - \\
& II & 92,6 & - & 5 & - \\
& III & 85,9 & - & 5 & - \\
Acorus colomus & IV & 74,9 & - & 4 & - \\
& V & 5,5 & - & 1 & - \\
& I & - & 49,5 & - & 3 \\
Andropogon nardus & II & - & 54,8 & - & 3 \\
& III & - & 51,8 & - & 3 \\
& IV & - & - & - & - \\
& V & - & - & - & - \\
& I & 94,5 & - & 5 & - \\
& II & 91,5 & - & 5 & - \\
& III & 80,7 & - & 5 & - \\
& IV & 70,9 & - & 4 & - \\
& V & 8,17 & - & 1 & - \\
\hline
\end{tabular}

tajam sehingga dapat bersifat repelen terhadap beberapa serangga. Tingginya sifat repelensi pada perlakuan sediaan butiran $V$. trifolia dapat dilihat dari kelas repelensi yang mencapai kelas 5 (Tabel 1). Persentase repelensi $V$. trifolia mulai dan pengamatan minggu ke-1 sampai pada pengamatan minggu ke-Ill berturut-turut 90,5\%, 92,6\%, dan $85,9 \%$. Hal yang sama terlihat pada persentase repelensi $A$. nardus, mulai pengamatan minggu ke-1 hingga ke-3 tingkat repelensi sangat tinggi sebesar $80,7 \%-94,5 \%$ dan mencapai kelas tertinggi dalam klasifikasi persentase repelensi. Ho et al. (1997) dalam Sylvia (1999) mengemukakan bahwa ekstrak tanaman dengan tingkat repelensi $>80 \%$ adalah bersifat sangat repelen. Tingginya tingkat repelensi dari sediaan butiran $V$. trifolia terhadap imago A. fasciculatus disebabkan karena sediaan butiran yang berasal dari bubuk daun $V$. trifolia tersebut memiliki aroma yang sangat tajam sehingga $A$. fasciculatus lebih cenderung datang ke biji kakao dibanding pellet $V$. trifolia. Heyne (2004) mengemukakan bahwa $V$. trifolia pada daunnya mengandung $0,28 \%$ berat kering minyak atsiri yang terdiri dari senyawa kamfen, sineol, terpinylatat dan pinen yang dapat bersifat repelen terhadap serangga tertentu. Hal yang sama terjadi pada sediaan A. nardus yang memiliki aroma yang sangat tajam, sehingga $A$. fasciculatus memilih untuk tidak mendatangi sediaan tersebut. Bagian batang dan daun $A$. nardus mengandung geraniol, metil 
heptenon, terpen-terpen, terpen-alkohol, asam-asam organik, dan kandungan terbesar adalah sitronela sebanyak $35 \%$ sebagai zat repelensi pada serangga. Menurut Mutchler, 1991. Mekanisme kerja sitronela dapat menghambat enzim asetilkolinesterase dengan melakukan fosforilasi asam amino sering pada pusat asteratik enzim serangga sehingga dapat menimbulkan gejala keracunan, gangguan system syaraf pusat, dan aktivitas penolakan makan yang akhirnya menyebabkan kematian pada serangga. Minyak atsiri dari $A$. nardus dapat digunakan sebagai insect repellent

Preferensi ketertarikan A. fasciculatus terhadap A. colomus disebabkan bau sediaan yang dihasilkan tidak terlalu tajam dibanding $A$. nardus dan $V$. trifolia. Ketertarikan A. fasciculatus terhadap A. colomus disebabkan karena adanya kandungan bahan kimia ekstrak berupa beta asorone dan beta caryophyllin yang merupakan sebuah ester yang berwujud minyak basa keras. Adanya kandungan ester tersebut yang dapat menarik serangga gudang untuk mendatangi sumber bau. Namun dalam penelitian ini tingkat ketertarikan hama gudang tersebut tidak tinggi hanya mencapai klas 3 atau berada pada kisaran ketertarikan 49,5\% hingga 54,8\%. Menurut Sylvia (1999) senyawa Beta Caryophyllin apabila dalam konsentrasi tinggi (85\%) dapat menyebabkan penurunan aktifitas gerak pada serangga.

\section{KESIMPULAN}

Sediaan butiran $V$. trifolia dan $A$. nardus bersifat menolak (repellent) sedangkan sediaan butiran $A$. colomus bersifat menarik (attractant) terhadap A. fasciculatus.

Daya tahan sediaan butiran Vitex trifolia dan $A$. andropogon nardus dalam menolak $A$. fasciculatus adalah 4 (empat) minggu sedangkan daya tahan sediaan butiran $A$. colomus dalam menarik A. fascicuiatus selama 3 (tiga) minggu.

\section{DAFTAR PUSTAKA}

[Anonim] 2002. Produksi Kakao. Dinas Perkebunan Provinsi Sulawesi Selatan.

Dobie P, Haimes CP, Hodges RJ, Prevett PF, Rees DP. 1991. Insects and Aracchnids of Tropical Stored Products: Their Biology and Identification. United Kingdom: Nasional Resources Institute (NRI).

Heyne K. 2004. Tanaman Berguna Indonesia, Jilid VI. Jakarta: Departemen Kehutanan.

Mutchler E. 1991. Dinamika Obat: Buku Ajar Farmakologi dan Toksikologi. Edisi 5. ITB. Bandung

Sylvia S. 1999. Beberapa bahan bioaktif tanaman yang bersifat repelen terhadap hama kacang buncis Acanthoscellides obtectus Say. (Coleoptera: Bruchidae). Phytomedicine 1: 6-9. 